\title{
Professional Networks Within U.S. Higher Education: Avenues to Foster Career and Institutional Success
}

\author{
Christian Teeter \\ Correspondence: Mount Saint Mary's University, Los Angeles, United States. \\ Received: Dec. 3, 2019 \\ Accepted: Apr. 24, 2020 \\ Online Published: Apr. 27, 2020 \\ doi:10.11114/jets.v8i6.4641 \\ URL: https://doi.org/10.11114/jets.v8i6.4641
}

\begin{abstract}
Within the United States, higher education is a ladder up to greater socioeconomic status. In spite of this fact, today's students need to focus on more than just completing their education. This scholarly essay focuses on the value of professional networks, in conjunction with institutions of higher learning, in career advancement and upward movement in socioeconomic levels. This essay emphasizes the role that professional networks play in enhancing the value of a bachelor's degree and provides evidence that students and institutions benefit from the development of professional networks both in support of the advancement of students' careers and in the engagement of alumni. The essay also demonstrates the benefits to academic institutions themselves when alumni engagement is fostered to a greater degree.
\end{abstract}

Keywords: professional networks, higher education, alumni affairs, career services

\section{Introduction}

Attainment of education today is perhaps the most critical element in the professional success that a person achieves throughout her or his lifetime. Education in all of its forms, however, provides skills and knowledge, but education in of itself does not guarantee access to the jobs and other areas of life that support the professional success so many desire to achieve. According to Doyle (2019), "At least 60\%...of all jobs are found by networking" (para. 3). As such, how can students today be equipped with the knowledge to make social connections that can grow their knowledge and establish the relationships needed to support their advancement and career growth? Colleges and universities, given the competitive nature of career searches prevailing today for undergraduates, can consider these issues more carefully in order to develop consistent and reliable career paths for graduates seeking employment and professional growth, in addition to advancement post-graduation. Competition in the labor market makes increased support all the more important: "As wages for even the lowest-paid positions continue to rise, experts believe it will become more difficult for workers to qualify for some entry-level positions for which they would have been perfect candidates even a few years ago" (ProLogistix, 2018, para. 2).

This scholarly essay addresses the essential role that professional networks provide students as they navigate their studies as well as when their studies have been completed. Diligence, drive, intelligence, focus, social skills, listening ability, and many other skills can contribute to one's career success. However, those qualities in themselves may not be enough to foster success and advancement in one's career. Given the intense competition that so many industries face, the burden on staff today to grow skills, attain new opportunities, and to advance, the complementary support of a professional network can make all of the difference in allowing a student to gain access to the career track she or he seeks. With these challenges and opportunities in the backdrop, what efforts can be made to prioritize professional networks, not only for students to build but for educational institutions to offer? In addition, what do institutions of higher learning themselves stand to gain by developing, and fostering professional networks for students and alumni?

\section{Background}

What is the value of a degree in today's job market? The advances of free trade and the consolidation of many industries in the United States leads to increased pressure on the youth of today to complete at least a bachelor's degree. Competition for job opportunities has become increasingly intense as the United States has transitioned from a manufacturing economy to an information economy focused more on professional services. As Kessels and Kwakman (2007) stated,

The increasing importance of knowledge in our society and economy also demands a shift in higher education in order to prepare students adequately to function within this type of society...they key resources that help organizations survive are becoming knowledge and expertise.... and that competencies such as curiosity, 
collaboration, and involvement will be the most important. (p. 692)

Given the importance of these competencies, a new focus within higher education is needed to give students practical experience to build and develop such competencies (Billett, 2001).

As such, the establishment of professional networks can assist in addressing this significant challenge related to the evolution of the domestic economy. Within the changing professional environment, and with so many more people attending college than in previous generations, a college education itself may not always be sufficient to foster career success. The students of today, in addition to having a major commitment to academic success, must pursue additional avenues that foster professional success, buffeting their academic training. Professional networks are one such avenue. Educators, in addition to ensuring the provision of a world-class offering in the classroom, can consider the value of professional networks within their work in the service of students and can provide support by offering a bridge that connects the abstract world of academics with the practical nature of the business environment. Marvin Krislov, president of Pace University, reinforces this idea supported by a strong career services approach: "We focus on a strong practical education grounded in the liberal arts...Our robust career services office ensures they (students) find great first jobs that start them on great careers" (para. 1). Thus, combining a strong education with career services offerings that help students make connections to graduates and others in the professional environment may make a significant difference in the outcomes of a student's career search.

\section{What Is a Professional Network?}

What is a professional network? A professional network is a group of contacts who are available to students and/or fellow professionals to provide guidance, insights, and, in some cases, mentorship and career support to fellow colleagues. This network could consist of fellow alumni from an educational institution and professors as well as current and former colleagues. A network can be considered as a "community of practice" that focuses on "community, identity, process and meaning" (Wenger, 1991, p. 93). As Niesz (2007) states, "What you do, who are in engagement with others, and whom you want to become are central" in the establishment of networks that support professional advancement (p. 606).

A major challenge, of course, is the structuring of these groups into organizational dimensions that can support student success as well as the continued growth of a specific institution's career development approaches. According to Paul LeMahieu (2015), a professional network is "a strategy to extend human capabilities in the pursuit of shared interests" (para. 2). Professional growth and development are critical elements that evolve from the fostering of shared interests within a network. Matt Walker, executive vice president of Lowe Enterprises, reinforces these points: "A professional network is a group of people that you associate with for business to grow yourself, developing both personally and professionally" (Personal communication, April 13, 2018 ). The emphasis on personal development cannot be ignored. Networks provide a lifelong support system to foster the growth in career and personal endeavors that sustains an individual through her or his career. Dr. Brian Casey, president of Colgate University, affirms the importance of the professional development aspects of a network, "It is where an institution intentionally connects current students and recent graduates to professionals who advance in a particular area" (Personal communication, April 9, 2018).

\section{The Importance of Higher Education}

Statistics today continue to emphasize the importance of completing a 4-year degree as opposed to a high school diploma. With the economy throughout 2019 generating record-low unemployment rates for college graduates, the evidence confirms that there is a major payoff from completing higher education (U.S. Bureau of Labor Statistics, 2019). Furthermore, college graduates earn as much as $74 \%$ more than individuals who complete a high school diploma (Carnevale, Rose, \& Cheah, 2010, p. 4). With the favorable economic benefits of completing a baccalaureate degree confirmed, what tools can be deployed to amplify the success of students in making career choices and navigating a very competitive labor market? In addition to economic concerns, skills development represents another crucial reason for individuals to pursue higher education. Concerning the U.S. labor market, the Spellings Commission (2006) noted, "Job categories that require only on-the-job training are expected to see the greatest decline. In high-demand fields, the value of postsecondary credentials and skills is likely to rise" (p. 7). With the evolving demands of the labor market, individuals also have to consider the value that education provides in terms of skill acquisition and development in addition to remuneration concerns.

While educators can guarantee that their offerings meet the highest intellectual and rigorous standards, why are there limitations to the success of graduates with just a focus on education alone? In other words, can a college graduate attain the level of success she or he aspires to with the completion of the degree alone?

\section{Problem: The Limitations of Higher Education}

Attainment of a baccalaureate degree makes all the difference, as noted above. The gains in lifetime income, as well as the consistently low unemployment for college graduates within the United States labor market, prove that higher education 
in itself pays off for elevating graduates' living standards.

What are the limitations? As Elisa Hernandez, director of career services at Columbia Basin College states,

Solely earning a college degree will not necessarily guarantee a successful career journey. A college degree is, in many fields, a vital part of obtaining a successful career but it is not the only factor. It is important to be mindful that career success also involves skills, determination, specialized knowledge of the field, and a strong professional network. (Personal communication, April 16, 2018)

As Siemens (2004) noted, just completing an education has limitations on knowledge, as well:

Learners as little as forty years ago would complete the required schooling and enter a career that would often last a lifetime...The life of knowledge was measured in decades. Today, these foundational principles have been altered. Knowledge is growing exponentially. In many fields, the life of knowledge is now measured in months and years. (p. 2)

Thus, the development of one's knowledge and skills, building upon the education one has obtained, plays a critical role in fostering success over a person's career. While the statistics support the economic benefits of education, how can the value of a college degree be amplified to a more powerful level to grow knowledge and also improve career options for graduates?

Colleges and universities, deploying their networks of successful graduates across a multitude of career tracks can offer resources to students, while also fostering the continued engagement of alumni, to afford students greater professional development opportunities and chances to grow their knowledge. These ideas are reinforced by Frederick Lawrence, chief executive and secretary of The Phi Beta Kappa Society:

In a field like law, for example, where there is a big difference between the formal training and practice, students have to be able to have help in both areas. School trains students in the academic, and a professional network helps them train in the practical aspects of the professional field. (Personal communication, April 20, 2018)

Lawrence's insights help reinforce the idea of practical knowledge adding value to complement the skills and ideas that are obtained through traditional academics. Further, individuals who participate in a professional network can tap it as a resource to close gaps in knowledge, supporting long-term career effectiveness (Grant, 2016).

In addition to building knowledge and career effectiveness, professional networks can also afford valuable opportunities for career advancement. Dr. Casey reinforces some of the limitations of higher education with respect to career development:

It [higher education] is necessary, but not sufficient. You have to determine how to step out of college... We rely on our alumni to detail the entry points into a profession because that is something that they are much better at than we are. (Personal communication, April 9, 2018)

A focus on academics remains essential, but participation in a network complements and builds upon the next steps for professionals as they anticipate entrance into the labor market. This point is emphasized by Carmine Di Sibio, global chairman and chief executive officer of Ernst \& Young who states, "The professional network helps build relationships and forms a bond. People can become clients, mentors and friends because they have a common ground from which to make connections" (Personal communication, April 18, 2019). Thus, networks support improved career success and satisfaction; people who participate and engage in professional networks have the potential to have more satisfying, fulfilling careers (Wolff \& Moser, 2009).

\section{Findings - The Benefits of Professional Networks}

Education in itself focuses on theories, scholarship, and other academic issues which do not always offer the most practical approach to problem solving or provide connections to real-world professional issues that arise in work environments. Professional networks can provide multiple rewards across constituencies of students, alumni, as well as to institutions themselves.

Benefits for students. Students participating in professional networking can benefit in numerous ways. Participating in a network can assist students in developing the resourcefulness that can bring about new opportunities for growth, advancement, and job placement. Mentoring is also another boon for student participants within a professional network. As Jeng, Drabavich and Margeton (1995) stated,

Mentors...inform students about career and employment opportunities from experience. They are reliable conduits of information about private and public employment, trends in job markets, what to expect in the way of job satisfaction, and what can be gained from joining a professional organization. (p. 347)

Thus, mentors can play a critical role in benefiting students who participate in a professional network in a variety of ways. 
Students of any discipline who wish to join a particular career path can benefit from a mechanism that helps to bridge the gap between the theoretical world of the classroom and the working environment that prevails within any job track. As such, a group of contacts connected to a specific area of business to assist and guide students can make a huge difference. As Joe McGrath, global head of banking at Barclays comments, "It is powerful, career-wise, to have a bunch of different networks to plug into" (Personal communication, April 12, 2018). Networks then allow participants to open doors that would otherwise be closed. Furthermore, developing and growing relationships within a professional network thus supports forward professional advancement. Ms. Hernandez reinforces this point:

When aiming to achieve career goals, the quality of your professional rapport with members in your network can make the difference between remaining stagnant in your career or moving up the management ladder...Success thus can be supported by strong relationships within the network itself, making a difference in a participant's career prospects. (Personal communication, April 16, 2018).

This approach can support and grow a person's long-term career earnings potential, fostered by greater career success (Wolff \& Moser, 2009). Mr. Di Sibio reinforces this point by noting, "A degree is a starting point. It helps you progress to a higher level. The professional network is an added benefit that increases chances of doing better by a good margin" (Personal communication, April 18, 2019). Thus, a strong network can assist a student in evolving from the purely academic environment to a greater focus on career advantage, increased knowledge, and higher earnings potential.

\section{Benefits to volunteer participants and alumni}

The benefits of participants in a network are emphasized by Lieberman and McGloughlin (1992): "Networks reward participants with a renewed sense of purpose and efficacy" (p. 674). Engagement with the alma mater as a mentor through professional networks can have a significant impact on the network volunteer. Mr. McGrath reinforces the opportunity: "Spending time with students for mentorship is a huge benefit" (Personal communication, April 12, 2018). Students gain knowledge and expertise, while those individuals volunteering time to the institution gain a greater sense of purpose and engagement with their alma mater. Further positive attributes of volunteer participation are emphasized by Mr. Lawrence:

You learn a lot about something when you teach it, having to articulate it and explain it - the process of learning and teaching. And most people find that it is rewarding to take their own experiences to help a person launching her or his career. Giving to others is an enormously rewarding experience. (Personal communication, April 20, 2018).

Thus, participation in a network has a comprehensive benefit, supporting those asking for assistance from the network, and also helping to reinforce those providing support and assistance within the network as well.

\section{Benefits to institutions}

Over the long term, recipients of services in professional networks can develop perspectives about their institution that inspires them to contribute and give back. With this insight, colleges, universities, and other institutions of learning can foster greater levels of participation over the long term. Institutions that establish and foster a strong network of graduates can benefit because those individuals are much more likely to be inclined to provide assistance to their institution (Cannon, 2015). Thus, institutions can benefit when alumni perceive that their volunteer experiences were rewarding. Mr. Lawrence reinforces this point:

If you can get people engaged in the institution, they may ask, 'Why should I support this? Because I am connected to it. I owe the start of my career to a connection from my school.' For the volunteer, in the midst of a busy life, this institution gave the person the chance to be valuable in a personally rewarding way. (Personal communication, April 20, 2018).

Thus, given this positive perception of the institution's contribution to the individual's professional success, institutions have more incentive to foster and build networking mechanisms.

Building upon the personal connections, graduates who participate in professional networks can develop a strong sense of personal satisfaction as they give back, inspiring them to do more. As Dr. Casey comments, "It keeps the institution vital to its alumni" (Personal communication, April 9, 2018). In addition, the establishment of professional networks themselves can build upon engagement of alumni and provide the college with many different rewards. Ms. Hernandez explains some of these benefits: "By fostering and emphasizing the importance of a professional network, the institution will create an ongoing culture that will encourage alumni engagement and ultimately benefiting the student population by facilitating professional growth" (Personal communication, April 16, 2018). With the kind of culture that Ms. Hernandez espouses, institutions of learning benefit because they can offer more to students and other participants in the network.

\section{Recommendations for Practice}

With many institutions of higher learning within the United States seeing declining enrollments and greater demands for 
career support services to help justify the high cost of college, it is important for educators today to evaluate and review the structure of their alumni functions. Institutions should consider approaches to greater engage alumni through advancement, volunteer opportunities, and corporate recruitment initiatives. These reviews should be aligned with specific strategic objectives already in place to ensure consistency with the institution's mission and long-term objectives. The evolution and growth of networks and alumni engagement could, over time, be promoted within recruitment activities, raising awareness of the benefits of the network for students and alumni as well. Institutions, articulating the value of giving back to the alma mater should reinforce to alumni that engagement and volunteering invest in the value of their degree, helping to raise the stature and prominence of the institution over time.

In addition to strategic steps with alumni outreach and advancement activities within the institution, institutions should harken back to the advice of Ms. Hernandez, focusing on the idea of a "culture" of alumni engagement that begins during the students' tenure on campus. The idea of "giving back" to the alma mater should be fostered from the outset of the person's engagement, with organizations reminding students that the connection begins from the date of the admission acceptance to the end of the person's life. Fostering these lifelong relationships can make a huge difference in the perspective of students as they navigate their education and after graduation as well. Along those lines, colleges and universities within the United States should emphasize the combination of academic excellence with student engagement in campus life. Dedication to study remains worthy and is the ultimate purpose of attending college, but the development of social skills and the strength of students to engage and interact with people whom they do not know well, makes all the difference in their ability to participate, effectively, within a network. Ms. Hernandez's comments about "rapport" within the network emphasize the importance of strong social skills and other approaches that help students foster strong relationships with people they know.

Those alumni volunteers working in a professional network should also be provided strategic advice about building relationships with students and recent graduates whom they support. For example, an institution could encourage its alumni to emphasize the importance of giving back to those that they serve, such that those individuals will be inspired to help others from the institution, who approach them at a later stage in life, for support. This would reinforce a culture of support encouraging all those who benefit from the professional network to eventually give back to it at some point later, sustaining its long-term vitality.

Institutions should also harness the talents and capabilities of faculty members to promote professional networking opportunities. Faculty members can foster their strong relationships with alumni and professional contacts to support opportunities for mentoring, recruitment, or informational interviews with employers. This dimension adds intellectual stimulation to the networking efforts, while also affording the institution access to a new realm of contacts not within its own alumni base.

In addition to relationships and career connections, institutions of higher learning should also reinforce the importance of today's knowledge economy, along with the significance of professionals being consistently focused on increasing expertise and skill in their professional areas. Students and alumni should be consistently afforded opportunities to grow knowledge and to share ideas in efforts to enhance their skills in the marketplace.

These recommendations, and other considerations, should be researched and possibly implemented in a strategic, as opposed to a piecemeal approach, giving the institution greater credibility and also elevating the chances of success in greater engagement with alumni and related stakeholders.

\section{Conclusion}

This essay has emphasized the limitations of the pursuit of higher education itself, alone, without a corresponding effort to engage in a professional network to foster greater career success. Professional networks afford institutions, and those who participate within them, many opportunities. Any student considering a higher education opportunity, whether a four-year program or an advanced degree, must evaluate the extent to which the institution supports students with advice, mentoring, and career support via an engaged alumni base, complementing the academic environment that prevails on campus. What is more, students, on their own, or with the advice of counselors and faculty, must come to terms with the understanding that the pursuit of academic excellence, while essential, does not do enough alone to foster future professional success. In the end, American colleges and universities, given the competitiveness of today's global economy, along with the possibility of stark declines in job opportunities for graduates, should see professional networks as a mission-critical necessity to assist students and to support the institution in the present while sustaining its future.

\section{Dedication}

This scholarly essay is dedicated to the Sisters of Saint Joseph of Carondelet, the founders of Mount Saint Mary's University, Los Angeles. 


\section{Acknowledgments}

Special thanks go to the respondents who participated in this essay. Without the generous provision of their time, knowledge, and insights, completion of this essay would not have been possible. The author also gives thanks to research assistants Josie DeBellis and Daniela Navarro for their support in the development of the essay.

\section{References}

Billett, S. (2001). Learning through work: Workforce affordances and individual engagement. Journal of Workplace Learning, 13(5), 209-214. https://doi.org/10.1108/EUM0000000005548

Cannon, T. (2015). The importance of the alumni network. Retrieved from https://doi.org/10.1016/S1353-4858(15)30006-4

Carnevale, A., Rose, S., \& Cheah, B. (2010). The college payoff. Washington: D.C. Georgetown University Center for Education \& The Workforce.

Doyle, A. (2019). How to use networking to find a job. Retrieved from https:/www.thebalancecareers.com/how-to-use-networking-to-find-a-job-2058686

Grant, R. (2016). The value of professional networking. Retrieved from: https://www.snhu.edu/about-us/newsroom/2016/05/value-of-professional-networking

Jeng, Dragovich and Margeton (1995). Alma mater mentoring: library science alumni promote school and profession. Journal for Education and Library Science, 4, 346-350.

Kessels, K., \& Kwakman, K. (2007). Establishing knowledge networks between higher vocational education and businesses. Higher Education, 54(5), 689-703. https://doi.org/10.1007/s10734-006-9018-4

Krislov, M. (2019, August 18). Some college programs pay off handsomely. The Wall Street Journal. Retrieved from https:/www.wsj.com/articles/some-college-programs-pay-off-handsomely-11566154498

LeMahieu, P. (2015). Why a Nic? Stanford, CA: Carnegie Foundation. Retrieved from https:/www.carnegiefoundation.org/blog/why-a-nic/

Lieberman, A.and McGloughlin, M.W. (1992). Networks for educational change. powerful and problematic. Phi Delta Kappan, 73(9), 673-677.

Niesz, T. (2007). Why teacher networks (can) work. Phi Delta Kappan, 88(8), 605-610. Retrieved from https://doi.org/10.1177/003172170708800812

ProLogistix. (2018). Competition keeps heating up for entry-level jobs nationwide. Retrieved from https://www.prologistix.com/news/2018/6/40175684/competition-keeps-heating-up-for-entry-level-jobs-nationwid e

Siemens, G. (2004). Connectivism: A learning theory for the digital age. Retrieved from http://www.elearnspace.org/Articles/connectivism.htm

Spellings Commission. (2006). A test of leadership. Washington, DC: Author. Retrieved from https:/www2.ed.gov/about/ bdscomm/list/hiedfuture/reports/final-report.pdf

U.S. Bureau of Labor Statistics. (2019). The employment situation, March 2019. Retrieved from https:/www.bls.gov/news.release/pdf/empsit.pdf

Wenger, E. (1991). Communities of practice: Learning, meaning and identity. Cambridge, UK: Cambridge University Press.

Wolff, H. G., \& Moser, K. (2009). Effects of networking on career success: A longitudinal study. The Journal of Applied Psychology, 94(1), 196-206. https://doi.org/10.1037/a0013350

\section{Copyrights}

Copyright for this article is retained by the author(s), with first publication rights granted to the journal.

This is an open-access article distributed under the terms and conditions of the Creative Commons Attribution license which permits unrestricted use, distribution, and reproduction in any medium, provided the original work is properly cited. 